\title{
Gas-phase structures of aminodifluorophosphines determined using electron diffraction data and computational techniques $\dagger$
}

\author{
Derek A. Wann, Sarah L. Hinchley and David W. H. Rankin* \\ School of Chemistry, University of Edinburgh, West Mains Road, Edinburgh, UK EH9 3JJ. \\ E-mail:d.w.h.rankin@ed.ac.uk
}

Received 3rd December 2004, Accepted 13th June 2005

First published as an Advance Article on the web 30th June 2005

The molecular structures of a family of eight aminodifluorophosphines, $\left(\mathrm{PF}_{2}\right) \mathrm{NRR}^{\prime}\left(\mathrm{R}, \mathrm{R}^{\prime}=\mathrm{H}, \mathrm{CH}_{3}, \mathrm{SiH}_{3}, \mathrm{GeH}_{3}\right.$, $\mathrm{PF}_{2}$ ), have been redetermined using gas-phase electron diffraction data and high-level ab initio molecular-orbital calculations. The SARACEN method has allowed the application of flexible restraints, giving greater accuracy and precision of structure, while the SHRINK program has allowed curvilinear corrections for vibrational effects to be applied to intramolecular distances. The more accurate structures of these eight compounds show consistent patterns of effects attributable to the various substituents, while conformations are dominated by the requirement that adjacent phosphorus and nitrogen lone pairs of electrons should be orthogonal.

\section{Introduction}

With advances in technological ability at relatively low costs, the use of computational methods for structure determination has grown rapidly in recent years. Information gained by performing ab initio calculations can be used in a number of different ways to improve upon structures previously determined by experiment alone. Local asymmetry within a molecular structure, often too subtle to be recognised in the past, may now be identified from optimised geometry calculations. Such calculations are useful for predicting the abundances of possible conformers from their relative energies. It is also possible to obtain theoretical harmonic force fields, thus allowing accurate amplitudes of vibration to be used in refinements and to derive vibrational correction terms.

The series of aminodifluorophosphines, $\left(\mathrm{PF}_{2}\right) \mathrm{NRR}^{\prime}\left(\mathrm{R}, \mathrm{R}^{\prime}=\right.$ $\mathrm{H}, \mathrm{CH}_{3}, \mathrm{SiH}_{3}, \mathrm{GeH}_{3}, \mathrm{PF}_{2}$; see Fig. 1 for a template structure), has been chosen as an example to show how the use of theoretical methods and gas-phase electron diffraction (GED) can combine to improve upon structures determined by GED alone, and can reveal structural patterns that might otherwise be missed.



Fig. 1 Template for aminodifluorophosphines 1-8: $\mathrm{R}=\mathrm{H}$ for $\mathbf{1}, \mathbf{3}$ and 8; $\mathrm{PF}_{2}$ for $\mathbf{2}, 5$ and $7 ; \mathrm{CH}_{3}$ for $\mathbf{4}$; and $\mathrm{SiH}_{3}$ for $\mathbf{6} . \mathrm{R}^{\prime}=\mathrm{PF}_{2}$ for $\mathbf{1}$ and $\mathbf{2}$; $\mathrm{CH}_{3}$ for 3 and $\mathbf{4} ; \mathrm{SiH}_{3}$ for $\mathbf{5 , 6}$ and $\mathbf{8}$; and $\mathrm{GeH}_{3}$ for 7 .

\section{Experimental}

\section{Ab initio calculations}

All calculations were performed using the Gaussian 98 suite of programs $^{1}$ on a Linux 12-processor Parallel Quantum Solutions (PQS) workstation. ${ }^{2}$ In each case a thorough search of the potential-energy surface of the molecule was performed at the RHF/3-21G* and RHF/6-31G* levels of theory., Allowing for complete rotation about each bond to nitrogen, all stable conformers were identified and calculations were continued to the MP2/6-311+G* level. ${ }^{5}$ (All MP2 calculations were frozen core.) For molecules 1-8 the coordinates for the geometry cal-

$\dagger$ Electronic supplementary information (ESI) available: Tables S1-S38; Figs. S1-S8. See http://dx.doi.org/10.1039/b418237e culated at the highest level are given in Tables $\mathrm{S} 1-8$, respectively (ESI $\dagger$ ).

For each molecule studied, a force field was calculated (RHF/6-31G*) to provide accurate amplitudes of vibration and vibrational correction terms for use in the refinement of the experimental data. The SHRINK program ${ }^{6}$ was employed, using a more reliable curvilinear representation of atomic motions rather than a rectilinear approximation.

\section{Gas-phase electron diffraction (GED)}

In total, eight members of the aminodifluorophosphine family were revisited during the course of this work. The reanalysis of the GED structures was carried out using the original experimental data. Where necessary the molecular-scattering intensity curves were scanned from the journals and digitised using the UnGraph program. ${ }^{7}$ This enabled sets of Cartesian coordinates describing the curves to be obtained and plotted to reconstruct the molecular-intensity curves.

The principles of the SARACEN (Structure Analysis Restrained by $A b$ initio Calculations for Electron diffractioN) method $^{8}$ were also employed. Parameters that are poorly defined by the GED experiment tend to refine to chemically unreasonable values and SARACEN allows flexible restraints to be applied to such parameters, thus allowing their inclusion in the refinement. Each restraint consists of a value (often the starting value for the parameter taken from the highest-level calculation) and an uncertainty (usually derived from the way that the parameter value differed through a series of graduated calculations).

\section{Results}

Table S9 (ESI $\dagger$ ) contains details (nozzle-to-plate distances, weighting functions, scale factors, correlation parameters and electron wavelengths) relating to the electron diffraction experiments carried out on the eight compounds.

\section{Bis(difluorophosphino)amine (1)}

Calculations identified the presence of two conformers of $\left(\mathrm{PF}_{2}\right)_{2} \mathrm{NH}, 1$, and the relative energies of these conformers at different levels of theory and with different basis sets are presented in Table S10 (ESI $\dagger$ ). Conformer 1 was calculated to have $C_{2 \mathrm{v}}$ symmetry and conformer 2 was calculated to have $C_{\mathrm{s}}$ symmetry. From the Boltzmann Law an energy difference of $1.4 \mathrm{~kJ} \mathrm{~mol}^{-1}$ would result in an abundance of $49 \%$ of conformer 
1 and $51 \%$ of conformer 2 . This takes into account the double multiplicity exhibited by conformer 2 .

In order to complete the refinement for 1, a model was written incorporating the geometries of both of the proposed conformers. The refinement of this combined model was used to determine the composition of the gas-phase sample in terms of conformers 1 and 2. The model was defined by thirteen independent geometric parameters and a weighting parameter to alter the composition of the mixture of conformers. These parameters are listed in Table S11 (ESI $\dagger$ ). As the two N-P distances in conformer 1 were calculated to be the same through symmetry, and this length was shared by one of the two distances for conformer 2, a simple average of the two distinct distances and the difference between them were used in the model. For the $\mathrm{P}-\mathrm{F}$ and $\mathrm{N}-\mathrm{H}$ bond lengths and the $\mathrm{F}-\mathrm{P}-\mathrm{F}$ angles the values for both conformers were similar enough that a single mean value was assumed in each case when writing the model. In the case of the $\mathrm{P}-\mathrm{N}-\mathrm{H}$ angles, three different values were calculated. In order to describe these, the simple average of all three was taken along with difference 1 (largest - intermediate) and difference 2 (largest - smallest). The three distinct angles were then described using the following equations:

for the largest angle, $\mathrm{P}-\mathrm{N}-\mathrm{H}=[$ average $+\{($ difference 1$) / 3\}+$ $\{($ difference 2$) / 3\}$,

for the intermediate angle, $\mathrm{P}-\mathrm{N}-\mathrm{H}=$ [average $-\{2 \times$ (difference 1$) / 3\}+\{($ difference 2$) / 3\}]$,

and for the smallest angle, $\mathrm{P}-\mathrm{N}-\mathrm{H}=[$ average $+\{$ (difference $1) / 3\}-\{2 \times($ difference 2$) / 3\}]$.

This approach was also adopted for the $\mathrm{N}-\mathrm{P}-\mathrm{F}$ angles, where the calculations suggested three different values.

Where differences between parameter values are extremely small, a tight restraint is often warranted and the SARACEN refinement will yield a value close to that of the restraint, and with an esd close to the uncertainty of the restraints. For this reason mean values are used to describe situations where parameters lie very close in value and the "average and difference" method is used where values are more significantly different.

Two torsion parameters describing the positions of the difluorophosphine groups were also refined, one each for conformers 1 and 2. These torsions were defined as being in the same sense for the $\mathrm{PF}_{2}$ groups in conformer 1 (i.e. the $\mathrm{PF}_{2}$ groups move to opposite sides of the PNP plane, allowing the molecule to distort from $C_{2 \mathrm{v}}$ to $C_{2}$ symmetry) and in the opposite sense for conformer 2 (i.e. they move to the same side of the PNP plane for $C_{\mathrm{s}}$ symmetry). The independent parameters and amplitudes (Table S12, ESI $\dagger$ ) were initially refined with a weighting of 0.5 , signifying a 50:50 mixture of conformers 1 and 2 . When the best fit was found for the model at this weighting, the composition was varied, using an $R$-factor loop in which the parameter was stepped by a given increment, to see how the fit was affected. In total thirteen parameters and nine amplitudes of vibration were refined, with flexible restraints applied to seven parameters and five amplitudes using the SARACEN method. Table 1 contains information relating to important geometric parameters.

Although the $a b$ initio calculations had predicted symmetry of $C_{2 \mathrm{v}}$ for conformer 1 and $C_{\mathrm{s}}$ for conformer 2, the refinement allowed the $\mathrm{PF}_{2}$ groups to rotate and concluded that conformer 1 had $C_{2}$ symmetry and conformer 2 had $C_{1}$ symmetry (Fig. 2). The structures determined by GED in this work are of the type $r_{h 1}$, in which corrections for curvilinear vibrational motions, calculated using the program SHRINK $^{6}$ are applied. Such structures differ from the equilibrium structures calculated $a b$ initio only in the anharmonic terms, and in any motion for which the curvature is not modelled adequately by the firstorder method used in SHRINK. Discrepancies between theory and experiment therefore arise primarily from one or both of these ways. This is quite possible for large-amplitude torsional motions, so in the molecular models used in the GED analysis, we allow the $\mathrm{PF}_{2}$ group torsional angles to refine, and do not fix



1
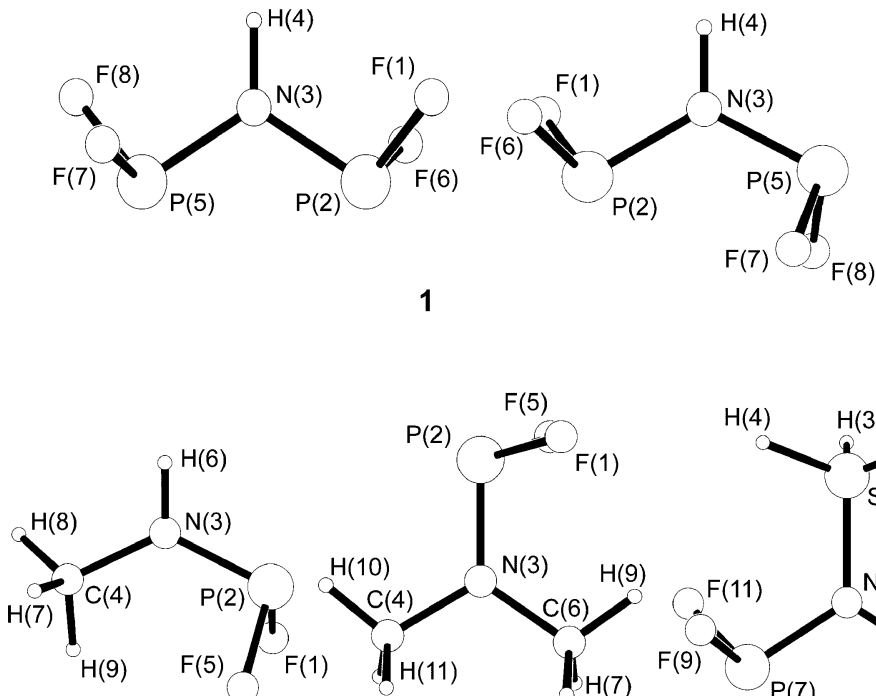

3

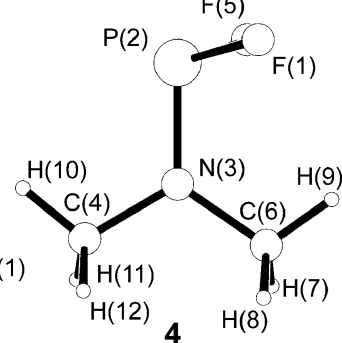

4

$\mathrm{H}(8)$

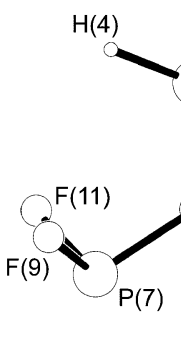

$\mathrm{H}(3)$

5
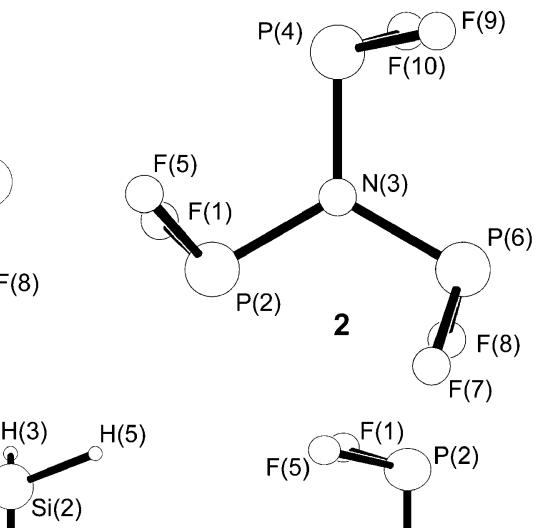

(5)
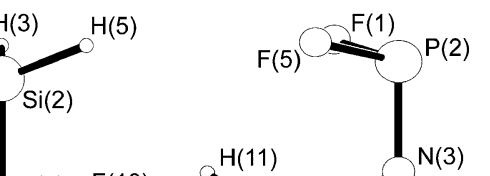

$(2)$
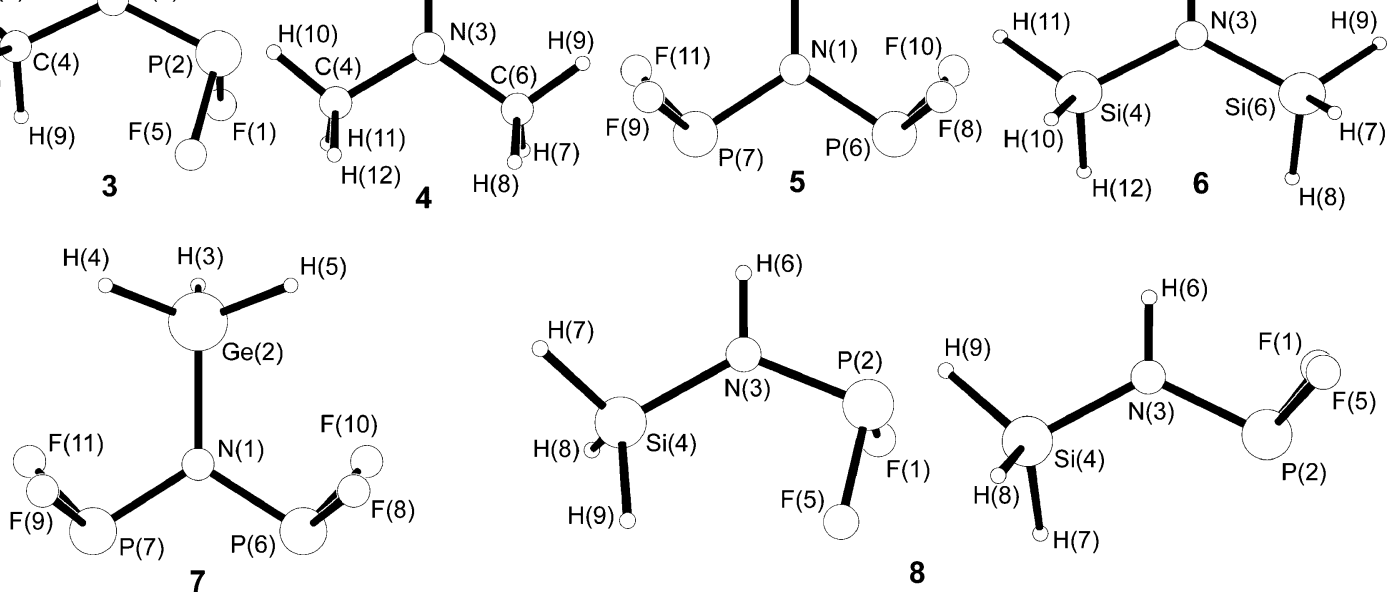

8

Fig. 2 Gas-phase structures of aminodifluorophosphines, 1-8. 
Table 1 Principal bond lengths, angles and torsions ${ }^{a}$ for compounds 1-8 from new refinements $\left(r_{h 1}\right)$, the highest-level $a b$ initio calculations $\left(r_{\mathrm{e}}\right)$ and the original refinements $\left(r_{\mathrm{a}}\right)$

\begin{tabular}{|c|c|c|c|c|c|c|c|c|}
\hline & 1 & 2 & 3 & 4 & 5 & 6 & 7 & 8 \\
\hline \multicolumn{9}{|c|}{ New refinements, $r_{h 1}$} \\
\hline \multirow[t]{2}{*}{$\mathrm{P}-\mathrm{F}$} & \multirow[t]{2}{*}{$157.8(1)$} & \multirow[t]{2}{*}{$156.4(1)$} & $163.3(4)$ & \multirow[t]{2}{*}{$159.2(4)$} & $156.8(2)$ & $158.5(3)$ & $159.5(3)$ & $159.3(2)^{b, c}$ \\
\hline & & & $163.9(4)$ & & $157.2(2)$ & $158.9(3)$ & $160.0(3)$ & $159.5(2)^{b}$ \\
\hline $\mathrm{P}-\mathrm{N}$ & $168.6(3)$ & $169.2(3)$ & $165.2(9)$ & $164.9(11)$ & $168.9(4)$ & $166.1(11)$ & $169.7(3)$ & $168.0(9)$ \\
\hline $\mathrm{N}-\mathrm{R}^{d}$ & $102.0(13)$ & $169.2(3)$ & $100.8(19)$ & $146.5(7)$ & $168.9(4)$ & $175.2(3)$ & $169.7(3)$ & $101.4(6)$ \\
\hline \multirow[t]{2}{*}{$\mathrm{N}-\mathrm{R}^{\prime e}$} & $168.6(3)^{b}$ & \multirow[t]{2}{*}{$169.2(3)$} & \multirow[t]{2}{*}{$150.7(4)$} & \multirow[t]{2}{*}{$146.5(7)$} & \multirow[t]{2}{*}{$177.9(10)$} & \multirow[t]{2}{*}{$176.6(3)$} & \multirow[t]{2}{*}{$190.8(5)$} & $175.6(7)^{b}$ \\
\hline & $170.0(3)^{c}$ & & & & & & & $174.4(7)^{c}$ \\
\hline \multirow{2}{*}{$\mathrm{P}-\mathrm{N}-\mathrm{R}^{d}$} & $121.3(5)^{b}$ & \multirow[t]{2}{*}{120 (fixed) } & \multirow[t]{2}{*}{$115.3(3)$} & \multirow[t]{2}{*}{$120.6(7)$} & \multirow[t]{2}{*}{$107.4(9)$} & \multirow[t]{2}{*}{$119.2(5)$} & \multirow[t]{2}{*}{$114.6(3)$} & $112.1(10)^{b}$ \\
\hline & $120.0(6)^{c}$ & & & & & & & $115.4(10)^{c}$ \\
\hline \multirow[t]{2}{*}{$\mathrm{P}-\mathrm{N}-\mathrm{R}^{\prime e}$} & $117.4(9)^{b}$ & \multirow{2}{*}{120 (fixed) } & \multirow[t]{2}{*}{$127.5(6)$} & $124.6(5)$ & $121.9(3)$ & $120.4(9)$ & $122.7(1)$ & $129.1(11)^{b}$ \\
\hline & $122.5(7)^{c}$ & & & & & & & $125.9(8)^{c}$ \\
\hline $\mathrm{R}-\mathrm{N}-\mathrm{R}^{\prime d, e}$ & $121.3(5)^{b}$ & 120 (fixed) & $115.5(8)$ & $114.8(10)$ & $121.9(3)$ & $120.4(10)$ & $122.7(1)$ & $115.4(10)^{b}$ \\
\hline & $117.4(8)^{c}$ & & & & & & & $118.8(13)^{c}$ \\
\hline $\mathrm{N}-\mathrm{P}-\mathrm{F}$ & $97.5(5)^{b}$ & $99.2(6)$ & $99.1(7)$ & $101.4(4)$ & $101.8(4)$ & $100.5(9)$ & $100.9(4)$ & $100.0(5)^{b}$ \\
\hline & $97.3(9)^{c}$ & & $102.0(7)$ & & $99.4(4)$ & $102.1(7)$ & $98.8(4)$ & $98.4(6)^{b}$ \\
\hline & $98.6(7)^{c}$ & & & & & & & $99.2(5)^{c}$ \\
\hline $\mathrm{F}-\mathrm{P}-\mathrm{F}$ & $96.9(5)$ & $98.1(9)$ & $92.6(4)$ & $95.3(5)$ & $97.4(5)$ & $96.3(4)$ & $96.6(7)$ & $95.4(5)$ \\
\hline Theoretical, & & & & & & & & \\
\hline $\mathrm{P}-\mathrm{F}$ & $161.2^{b}$ & 161.2 & 162.6 & 163.2 & 161.4 & 162.5 & 161.8 & $162.4^{b, c}$ \\
\hline & $161.4^{c}$ & & 163.2 & & 161.8 & 162.9 & 162.3 & $162.6^{b}$ \\
\hline $\mathrm{P}-\mathrm{N}$ & 169.0 & 173.5 & 165.3 & 165.3 & 170.1 & 167.5 & 169.1 & 166.6 \\
\hline $\mathrm{N}-\mathrm{R}^{d}$ & $102.1^{b}$ & 173.5 & 101.0 & 146.0 & 170.1 & 178.3 & 169.1 & $101.3^{b}$ \\
\hline & $101.7^{c}$ & & & & & & & $101.8^{c}$ \\
\hline $\mathrm{N}-\mathrm{R}^{\prime e}$ & $169.0^{b}$ & 173.5 & 146.5 & 146.0 & 181.7 & 178.8 & 193.6 & $177.3^{b}$ \\
\hline & $170.4^{c}$ & & & & & & & $176.2^{c}$ \\
\hline $\mathrm{P}-\mathrm{N}-\mathrm{R}^{d}$ & $118.4^{b}$ & 120.0 & 115.3 & 120.3 & 114.8 & 119.4 & 116.2 & $112.4^{b}$ \\
\hline & $114.4^{c}$ & & & & & & & $115.6^{c}$ \\
\hline $\mathrm{P}-\mathrm{N}-\mathrm{R}^{\prime e}$ & $123.3^{b}$ & 120.0 & 126.5 & 124.5 & 122.6 & 122.4 & 121.9 & $130.0^{b}$ \\
\hline & $128.5^{c}$ & & & & & & & $126.4^{c}$ \\
\hline $\mathrm{R}-\mathrm{N}-\mathrm{R}^{\prime d, e}$ & $118.4^{b}$ & 120.0 & 116.6 & 115.2 & 122.6 & 118.1 & 121.9 & $117.6^{b}$ \\
\hline & $117.1^{c}$ & & & & & & & $118.0^{c}$ \\
\hline $\mathrm{N}-\mathrm{P}-\mathrm{F}$ & $98.8^{b}$ & 98.0 & 99.4 & 101.0 & 100.4 & 98.8 & 100.4 & $100.9^{b}$ \\
\hline & $98.0^{c}$ & & 101.6 & & 97.7 & 101.3 & 97.9 & $99.3^{b}$ \\
\hline & $99.5^{c}$ & & & & & & & $100.1^{c}$ \\
\hline $\mathrm{F}-\mathrm{P}-\mathrm{F}$ & 95.2 & 95.9 & 93.3 & 92.8 & 95.5 & 94.6 & 95.0 & 94.2 \\
\hline Old refiner & & & & & & & & \\
\hline $\mathrm{P}-\mathrm{F}$ & $158.4(3)$ & $157.4(2)$ & $159.3(4)$ & $158.9(3)$ & $157.0(2)$ & $158.5(3)$ & $159.2(5)$ & $157.4(3)$ \\
\hline $\mathrm{P}-\mathrm{N}$ & $168.4(8)$ & $171.2(4)$ & $164.8(7)$ & $164.8(8)$ & $169.1(4)$ & $168.0(4)$ & $169.8(8)$ & $165.7(7)$ \\
\hline $\mathrm{N}-\mathrm{R}^{d}$ & $97.3(23)$ & $171.2(4)$ & 100.0 (fixed) & $144.8(6)$ & $169.1(4)$ & $175.5(4)$ & $169.8(8)$ & 99.8 \\
\hline $\mathrm{N}-\mathrm{R}^{\prime e}$ & $168.4(8)$ & $171.2(4)$ & $144.8(12)$ & $144.8(6)$ & $176.7(7)$ & $175.5(4)$ & $188.9(13)$ & $172.0(8)$ \\
\hline $\mathrm{P}-\mathrm{N}-\mathrm{R}^{d}$ & - & 120 (fixed) & 118.0 (fixed) & $118.3(6)$ & $117.6(7)$ & - & $114.0(8)$ & 118.8 \\
\hline $\mathrm{P}-\mathrm{N}-\mathrm{R}^{\prime e}$ & $122.1(7)$ & 120 (fixed) & $125.3(20)$ & $118.3(6)$ & - & - & — & $127.9(7)$ \\
\hline $\mathrm{R}-\mathrm{N}-\mathrm{R}^{\prime d, e}$ & - & 120 (fixed) & - & $111.8(15)$ & - & $120.0(15)$ & - & — \\
\hline $\mathrm{N}-\mathrm{P}-\mathrm{F}$ & $98.3(7)$ & $99.0(4)$ & $100.6(4)$ & $97(4)$ & $99.3(3)$ & $99.4(7)$ & $99.6(5)$ & 95.6 \\
\hline $\mathrm{F}-\mathrm{P}-\mathrm{F}$ & $95.6(10)$ & $97.1(5)$ & $94.1(8)$ & $99(3)$ & $96.1(5)$ & $96.9(10)$ & $96.5(11)$ & $100.8(12)$ \\
\hline
\end{tabular}

${ }^{a}$ Distances are in pm, angles in degrees. The figures in parentheses are the estimated standard deviations of the last digits. ${ }^{b}$ Conformer $1 .{ }^{c}$ Conformer

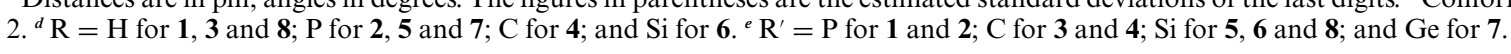

them exactly at the values calculated $a b$ initio. The refined values do not therefore represent any time average of deviations from the mean positions, but are merely fitting parameters, which take account of any deficiencies in the vibrational modelling.

It would be possible to perform a refinement using a socalled 'dynamic model', as was used in the study of $\mathrm{NMe}\left(\mathrm{PF}_{2}\right)_{2}$ thirty years ago. ${ }^{9}$ However, in such an approach the two torsional modes are treated explicitly, while the effects of other vibrations are ignored, or dealt with using conventional vibrational analysis. The final structure is thus not of type $r_{\mathrm{a}}$, $r_{h 1}$ or indeed of any other specifically defined type. In this study, in which structures of a series of compounds are compared, we believe that it is important that all are treated in the same way, and we have therefore not performed such an analysis in this case.
For a composition with $46 \%$ of conformer 1 and $54 \%$ of conformer 2 present, the lowest $R_{\mathrm{G}}$ value of 0.040 was obtained. Fig. S1 (ESI $\dagger$ ) shows the radial-distribution curve and the theoretical - experimental difference curve for the joint refinement assuming the abundance of conformer 1 to be $46 \%$. The least-squares correlation matrix for the final refinement is given in Table S13 (ESI $\dagger$ ).

Fig. 3 is a plot of the change in $R_{\mathrm{G}}$ value with change in the weighting of conformer 1 . This plot can be used ${ }^{10}$ to obtain an uncertainty associated with the weighting parameter. At a significance level of $95 \%$ (for which the $R_{\mathrm{G}}$ ratio is calculated to be 1.016), the abundance of conformer 1 is $46(3) \%$. This corresponds approximately to an esd of $2 \%$.

The original GED refinement ${ }^{11}\left(R_{\mathrm{G}}=5.7 \%\right)$ agrees with this work in concluding that there were two distinct conformers of 


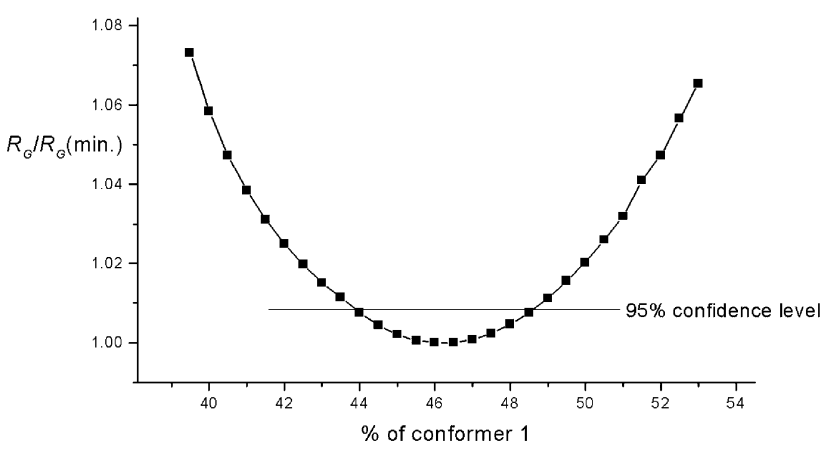

Fig. 3 Variations of $R_{\mathrm{G}}$ with percentage of conformer 1 of $\left(\mathrm{PF}_{2}\right)_{2} \mathrm{NH}$, 1.

bis(difluorophosphino)amine. In that study, the predominant (lower-energy) form was found to be $72 \%$ abundant and had $C_{2 \mathrm{v}}$ symmetry. In the higher-energy form, one $\mathrm{PF}_{2}$ group was twisted about $60^{\circ}$ away from the $C_{2 \mathrm{v}}$ position. A study of the vibrational spectrum of this compound in the gas phase also predicted the presence of two conformers by showing two distinct $\mathrm{N}-\mathrm{H}$ stretches and two $\mathrm{N}-\mathrm{H}$ deformations. ${ }^{12}$ The original refinement was, however, wrong to assume that the $\mathrm{P}-\mathrm{N}-\mathrm{P}$ angles in both conformers were identical. Calculations show that the angles differ by more than $5^{\circ}$ between the conformers and one of the most significant improvements made to the refinement has been allowing the $\mathrm{P}-\mathrm{N}-\mathrm{P}$ angles to differ.

\section{Tris(difluorophosphino)amine (2)}

A search of the potential-energy surface of $\mathrm{N}\left(\mathrm{PF}_{2}\right)_{3}, \mathbf{2}$, yielded a single conformer. The calculations found the molecule to have a planar nitrogen skeleton, in which all three phosphorus lone pairs lie perpendicular to the axis of the nitrogen lone-pair orbital. The $\mathrm{PF}_{2}$ ligands surrounding nitrogen are arranged in a triskelion manner (similar to that found on the flag of the Isle of Man) giving the molecule overall $C_{3 \mathrm{~h}}$ symmetry.

The structure of $\mathbf{2}$ was described in a model in terms of five independent geometric parameters, which are listed in Table S14 (ESI $\dagger$ ). It was assumed that all $\mathrm{PF}_{2}$ groups were identical and had a plane of symmetry and that the $\mathrm{NP}_{3}$ motif was planar. The model allowed the $\mathrm{PF}_{2}$ groups to twist away from their $C_{3 \mathrm{~h}}$ positions, all in the same direction, giving the molecule overall $C_{3}$ symmetry. All five parameters and nine amplitudes of vibration (Table S15, ESI $\dagger$ ) were allowed to refine with four amplitudes requiring to be restrained using the SARACEN method. Table 1 shows the principal bond lengths, angles and torsion and compares these to the original refinement and the highest-level $a b$ initio calculation. The gas-phase structure of $\mathbf{2}$ is shown in Fig. 2.

The $R_{\mathrm{G}}$ value obtained for the refinement was 0.049 . The goodness of fit can be seen in the experimental - theoretical difference curve shown in Fig. S2 (ESI $\dagger$ ). The least-squares correlation matrix for the final refinement is given in Table S16 (ESI $\dagger$ ).

The original refinement,${ }^{13}$ with an $R_{\mathrm{G}}$ value of 0.080 , agrees with this work that the molecule has a planar skeleton, which was also the case with the GED structure of the silicon analogue, trisilylamine. ${ }^{14}$ A study of $\mathrm{N}\left(\mathrm{PF}_{2}\right)_{3}$ using various spectroscopic techniques (IR, Raman, NMR, mass and PE spectroscopies) could not provide a conclusive determination of the positions of the $\mathrm{PF}_{2}$ groups and, therefore, the overall symmetry. ${ }^{12}$ The authors "tentatively suggest" that a mixture of conformers, one with $C_{\mathrm{s}}$ symmetry and the other with $C_{3}$ symmetry, may have best fitted the spectroscopic data. This seems unlikely and the $C_{3}$ model favoured by GED appears to be more reasonable, with the $\mathrm{PF}_{2}$ groups rotated slightly $\left(\sim 9^{\circ}\right)$ from the $C_{3 \mathrm{~h}}$ position.

\section{Methylaminodifluorophosphine (3)}

Calculations at the RHF/6-31G* level gave rise to two conformers of $\left(\mathrm{PF}_{2}\right) \mathrm{NH}\left(\mathrm{CH}_{3}\right), 3$. Both conformers were found to have a slightly pyramidal arrangement of ligands around the central nitrogen, with the total angle around $\mathrm{N}$ being approximately $358^{\circ}$. Both structures had $C_{1}$ symmetry and the main difference between the two was the orientation of the $\mathrm{PF}_{2}$ group. In the lower-energy conformer, the fluorine atoms were positioned as far away from the amino hydrogen as possible, i.e. with the phosphorus lone pair of electrons approximately eclipsing the $\mathrm{N}-\mathrm{H}$ bond; the opposite was found for the structure with higher energy, i.e. with the phosphorus lone pair anti with respect to the $\mathrm{N}-\mathrm{H}$ bond. The differences in energy between the two conformers at various levels of theory and using different basis sets are shown in Table S17 (ESI $\dagger$ ). The energy difference between the two conformers of $7.1 \mathrm{~kJ} \mathrm{~mol}^{-1}$ at the highest level of calculation means that the higher-energy one is likely to be found in a very low abundance in a gas-phase sample. A Boltzmann distribution analysis estimates that the conformer will contribute only around $5 \%$ of a gas sample at 296 K. For this reason, a single-conformer refinement was performed for the structure shown in Fig. 2.

A model was written describing the geometry of $\mathbf{3}$ in terms of sixteen independent parameters, listed in Table S18 (ESI $\dagger$ ). These parameters include six bond lengths and differences, six angles and differences, and a parameter describing the twist of the $\mathrm{PF}_{2}$ group away from the position where the $\mathrm{P}-\mathrm{F}(5)$ bond eclipses the $\mathrm{C}-\mathrm{N}$ bond. There is also a parameter for the torsion of the methyl group, about its $\mathrm{C}-\mathrm{N}$ bond, where the zero position is where the $\mathrm{C}-\mathrm{H}(7)$ bond eclipses the $\mathrm{N}-\mathrm{H}$ bond and a positive value is taken as a rotation in the clockwise direction while viewing from $\mathrm{N}$ to $\mathrm{C}$. The tilt of the methyl group, so that the centroid of the $\mathrm{H} \cdots \mathrm{H} \cdots \mathrm{H}$ triangle lies either above or below the CNP plane, and where a negative value indicates a move to the opposite side of the plane to the apex of the pyramid, is also included. Lastly there is the parameter describing the drop from the PNC plane of $\mathrm{H}(6)$ to make the molecule slightly pyramidal.

Sixteen independent parameters and seven amplitudes of vibration (Table S19, ESI $\dagger$ ) were refined, with eight parameters and four amplitudes being restrained using the SARACEN method to prevent them refining to chemically unreasonable values. Table 1 contains details of the principal bond lengths, angles and torsions. The value obtained for the $R_{\mathrm{G}}$ factor was 0.039 and this small value is reflected in the smoothness of the experimental - theoretical difference curve in Fig. S3 (ESI $\dagger$ ). The least-squares correlation matrix for the final refinement is shown in Table S20 (ESI $\dagger$ ).

The original refinement ${ }^{15}$ failed to quote a value for $R_{\mathrm{G}}$ and it was suspected that the molecule had coplanar bonds to the central nitrogen. This seems to be wrong based on our calculations and refinement. As the infrared spectrum showed two $\mathrm{N}-\mathrm{H}$ stretches, it was suggested that there were two conformers of $\mathbf{3}$ present in the sample. However, the intensities of these stretches are in the ratio $10: 1$ and we now believe that any second conformer would be so much higher in energy that it would be unlikely to be observed in the GED experiment, which is unreliable for the determination of amounts less than approximately $20 \%$.

\section{Dimethylaminodifluorophosphine (4)}

A thorough search for conformers of $\left(\mathrm{PF}_{2}\right) \mathrm{N}\left(\mathrm{CH}_{3}\right)_{2}, 4$, showed only one structure, with overall $C_{\mathrm{s}}$ symmetry and bonds to nitrogen that are coplanar.

Based on calculations (MP2/6-311+G*), a model was written to describe the geometry of the molecule with $C_{\mathrm{s}}$ symmetry in terms of thirteen independent geometric parameters, comprising five bond lengths and differences, five bond angles and three torsion parameters, as shown in Table S21a (ESI $\dagger$ ). It was assumed that the $\mathrm{N}\left(\mathrm{CH}_{3}\right)$ groups had $C_{3 \mathrm{v}}$ local symmetry and 
that the $\mathrm{PF}_{2}$ group had a plane of symmetry. A microwave spectrum ${ }^{16}$ for $\left(\mathrm{PF}_{2}\right) \mathrm{N}\left(\mathrm{CH}_{3}\right)_{2}$ had been recorded and rotational constants, corrected using SHRINK, were included in the refinement as extra data. The refinement was repeated, this time excluding the rotational constants. Although the structure itself changes very little (see Table S21b, ESI $\dagger$ ), parameters become less well defined and a need arises to restrain additional torsion parameters, thereby substituting experimental data for theoretical. In particular, the torsion on the $\mathrm{PF}_{2}$ group is well defined when the microwave data are included but much less so without them. The methyl torsions both show very large esds implying that there is little information about their values.

In total thirteen parameters and ten amplitudes of vibration were refined. (For full details see Table S22, ESI. $\dagger$ ) Flexible restraints were applied to four parameters and to six amplitudes. Table 1 lists important bond lengths, angles and torsion angles from the least-squares refinement and the molecular structure is shown in Fig. 2. The refinement achieved an $R_{\mathrm{G}}$ value of 0.097 with the worst fitting of data coming at longer distances. The radial-distribution curve and associated experimental theoretical difference curve are shown in Fig. S4 (ESI $\dagger$ ). The least-squares correlation matrix for the final refinement is shown in Table S23 (ESI $\dagger$ ). For the refinement that was undertaken without the rotational constants, an $R_{\mathrm{G}}$ value of 0.087 was achieved. Despite this modest improvement, we believe that the refinement that includes extra experimental data is better.

The original GED refinement ${ }^{17}$ for 4 gave an $R_{\mathrm{G}}$ value of 0.12 for a structure that was non-planar. (The total angle around $\mathrm{N}$ was thought to be $348.4^{\circ}$.) This is in contrast to the microwave structure ${ }^{16}$ and an X-ray analysis of the solid phase, ${ }^{18}$ both of which show planar structures, as did our calculations and refinement. To probe how easily 4 can become nonplanar, calculations were performed (MP2/6-311+G*) where the geometry of the molecule was optimised as the $\mathrm{C}-\mathrm{N}-\mathrm{P}-\mathrm{C}$ torsion angle was stepped from 140 to $220^{\circ}$. The torsion angle of $180^{\circ}$ represents a molecule that is planar about the nitrogen atom and the most extreme cases correspond to molecules where the sum of the angles at $\mathrm{N}$ was $347^{\circ}$. It was found that while the potential for C-N-P-C was very shallow within $30^{\circ}$ of $180^{\circ}$ $\left(\Delta E \leq 0.3 \mathrm{~kJ} \mathrm{~mol}^{-1}\right)$ the energy rose sharply for narrower angles.

\section{Bis(difluorophosphino)silylamine (5)}

A search for possible conformers of $\left(\mathrm{PF}_{2}\right)_{2} \mathrm{~N}\left(\mathrm{SiH}_{3}\right), \mathbf{5}$, resulted in two structures whose energies differed by $5.3 \mathrm{~kJ} \mathrm{~mol}^{-1}$ (MP2/6-311+G*; see Table S24, ESI, $\dagger$ for all energies). Both structures exhibit planar nitrogen centres and differ mainly in the twist of the $\mathrm{PF}_{2}$ groups. The lower-energy conformer 1 was calculated with $C_{\mathrm{s}}$ symmetry and has the phosphorus lone pairs of electrons pointing towards each other, with the fluorine atoms in the direction of the silyl hydrogens. The higher-energy structure (conformer 2) had $C_{1}$ symmetry, with one $\mathrm{PF}_{2}$ group rotated through $180^{\circ}$ from the position seen in the lower-energy conformer. For an energy difference of $5.3 \mathrm{~kJ} \mathrm{~mol}^{-1}$, a Boltzmann analysis suggests that the composition of a gas-phase sample at the experimental temperature $(293 \mathrm{~K})$ will be $82 \%$ conformer 1 and $18 \%$ conformer 2 .

Initially, a model was written to describe $\mathbf{5}$ in terms of both conformers with a weighting parameter to change the composition of the mixture. However, as it became apparent that the best fit to the experimental data occurred when none of the higher-energy conformer was included, we reverted to a singleconformer model of the $C_{\mathrm{s}}$-symmetry structure. The model was described in terms of five bond lengths and differences, five angles and differences and two torsion parameters, one each for the $\mathrm{PF}_{2}$ and silyl twists (see Table S25, ESI, $\dagger$ for a full parameter list). It was assumed that the $\mathrm{N}\left(\mathrm{SiH}_{3}\right)$ group had local $C_{3 \mathrm{v}}$ symmetry and that the two $\mathrm{PF}_{2}$ groups were identical. In total twelve parameters and fourteen amplitudes of vibration (Table S26, ESI $\dagger$ ) were refined. Flexible restraints were applied to three parameters and to six amplitudes. The principal refined parameters are listed in Table 1.

The outcome of the refinement for 5 was an $R_{\mathrm{G}}$ value of 0.041 and the structure is shown in Fig. 2. The radial-distribution curve, with its associated difference curve (Fig. S5, ESI $\dagger$ ), also shows the goodness of fit and suggests that it was indeed correct to ignore the contribution of any other conformer. Table S27 (ESI $\dagger$ ) shows the least-squares correlation matrix for the final refinement.

The original refinement, ${ }^{19}$ with an $R_{\mathrm{G}}$ value of 0.06 , agreed with this study that 5 consists of a single conformer of $C_{\mathrm{s}}$ symmetry.

\section{Difluorophosphino(disilyl)amine (6)}

A single conformer of $\left(\mathrm{PF}_{2}\right) \mathrm{N}\left(\mathrm{SiH}_{3}\right)_{2}, 6$, (Fig. 2) was calculated to have $C_{1}$ symmetry, having two distinct $\mathrm{P}-\mathrm{F}$ distances and silyl groups that were twisted to different degrees, therefore precluding $C_{\mathrm{s}}$ symmetry. A model was written describing the structure in terms of fifteen independent geometric parameters, comprising six bond lengths and differences, six bond angles and differences and three torsion parameters, one for each of the silyl groups and one for the $\mathrm{PF}_{2}$ group. (These are listed in Table S28, ESI. $\dagger$ ) The N-Si distances and the P-N-Si and N-P$\mathrm{F}$ angles are defined in terms of an average value and a difference. This results in no symmetry being implied for the molecule as a whole, although the $\mathrm{N}\left(\mathrm{SiH}_{3}\right)$ groups are defined to possess local $C_{3 \mathrm{v}}$ symmetry, a good approximation. The silyl torsion parameters are the rotations of the respective groups about their $\mathrm{Si}-\mathrm{N}$ axes from zero-torsion positions where the $\mathrm{Si}(4)-\mathrm{H}(12)$ bond for $\mathrm{Si}(4) \mathrm{H}_{3}$ and the $\mathrm{Si}(6)-\mathrm{H}(8)$ bond for $\mathrm{Si}(6) \mathrm{H}_{3}$ eclipse the opposite $\mathrm{N}-\mathrm{Si}$ bonds. A positive value is defined as rotation in the clockwise direction as viewed from Si to N.

In total fifteen parameters and ten amplitudes of vibrations (Table S29, ESI $\dagger$ ) were refined. Flexible restraints were applied to five parameters and to four amplitudes of vibration. Table 1 contains the principal parameters associated with the structure of 6 .

The outcome of the final refinement for $\left(\mathrm{PF}_{2}\right) \mathrm{N}\left(\mathrm{SiH}_{3}\right)_{2}$ was an $R_{\mathrm{G}}$ value of 0.031 . The radial-distribution curve (Fig. S6, ESI $\dagger$ ) with its associated difference curve also shows the goodness of the final fit. The least-squares correlation matrix for the final refinement is given in Table $\mathrm{S} 30$ (ESI $\dagger$ ). The original refinement ${ }^{20}$ concluded that the $R_{\mathrm{G}}$ value was 0.08 , with the proposed structure in good agreement with that determined here.

\section{Bis(difluorophosphino)germylamine (7)}

An extensive search of the potential-energy surface of $\left(\mathrm{PF}_{2}\right)_{2} \mathrm{~N}\left(\mathrm{GeH}_{3}\right), 7$, resulted in the identification of two conformers. A lower-energy conformer with overall $C_{\mathrm{s}}$ symmetry (conformer 1) is close to $C_{2 \mathrm{v}}$ symmetry for the $\mathrm{GeN}\left(\mathrm{PF}_{2}\right)_{2}$ group, while the higher-energy conformer with $C_{1}$ symmetry has one $\mathrm{PF}_{2}$ group rotated approximately $180^{\circ}$ from the position in conformer 1 . The two conformers have significantly different energies (Table S31, ESI $\dagger$ ). At the MP2/6-311+G* level, the energy difference between the two conformers was found to be $7.8 \mathrm{~kJ} \mathrm{~mol}^{-1}$. This corresponds to a composition of approximately $93 \%$ conformer 1 and $7 \%$ conformer 2 , recognising that conformer 2 has a double multiplicity.

The model used for the refinement of 7 therefore described only the $C_{\mathrm{s}}$-symmetry conformer, in terms of 12 independent parameters (Table S32, ESI $\dagger$ ). All twelve independent parameters and twelve significant amplitudes of vibration (Table S33, ESI $\dagger$ ) were refined, with flexible restraints applied to five geometric parameters and four amplitudes. Principal parameters are listed in Table 1.

The refinement for 7 revealed the structure shown in Fig. 2, with an $R_{\mathrm{G}}$ value of 0.047 . The radial-distribution curve and its associated difference curve (Fig. S7, ESI $\dagger$ ) show the goodness 
of fit and the least-squares correlation matrix is shown in Table S34 (ESI $\dagger$ ).

The outcome of the original refinement ${ }^{19}$ was an $R_{\mathrm{G}}$ value of 0.12 . Although the structures obtained from that study and this are very similar, a better fit to the data was produced by removing some of the data from the longer nozzle-to-plate set because there was poor overlap between the data sets.

\section{Silylaminodifluorophosphine (8)}

An extensive search of the potential-energy surface of $\left(\mathrm{PF}_{2}\right) \mathrm{NH}\left(\mathrm{SiH}_{3}\right), 8$, revealed the presence of two conformers (Fig. 2), the relative energies of which are shown in Table S35 (ESI $\dagger$ ). Conformer 1 was calculated to have $C_{1}$ symmetry and conformer 2 to have $C_{\mathrm{s}}$ symmetry. A Boltzmann analysis of the composition of the sample at the experimental temperature $(273 \mathrm{~K})$ indicates that an energy difference of $0.5 \mathrm{~kJ} \mathrm{~mol}^{-1}$ will result in a sample composed of $71 \%$ of conformer 1 and $29 \%$ of conformer 2, allowing for the double multiplicity of conformer 1 .

A model was written incorporating the geometries of both of the proposed conformers. The refinement of this combined model would be used to determine the composition of the gasphase sample in terms of conformers 1 and 2. The joint model was defined by twenty-three independent geometric parameters and a conformer-weighting parameter. (Full details are given in Table S36, ESI. $\dagger$ ) To account for the major differences between the two conformers, average values and differences were used for most of the bond-length and angle parameters. Two torsion parameters describing the positions of the difluorophosphine groups were also refined, one each for conformers 1 and 2 . The parameters and amplitudes (Table S37, ESI $\dagger$ ) were initially refined with a weighting of 0.5 , signifying a $50: 50$ mixture of conformers 1 and 2. When the best fit had been found for the model at this weighting, the composition was varied, using an $R$-factor loop in which the parameter was stepped by a given increment, to see how the fit was affected. An uncertainty associated with the refined percentage of conformer 1 was obtained ${ }^{9}$ from Fig. 4. At a significance level of $95 \%$ (for which the $R_{\mathrm{G}}$ ratio is calculated to be 1.016), the abundance of conformer 1 is $54(+2 /-5) \%$, which is equivalent to an energy difference of $1.2 \mathrm{~kJ} \mathrm{~mol}^{-1}$. The principal bond lengths, angles and torsions for $\mathbf{8}$ are given in Table 1 .

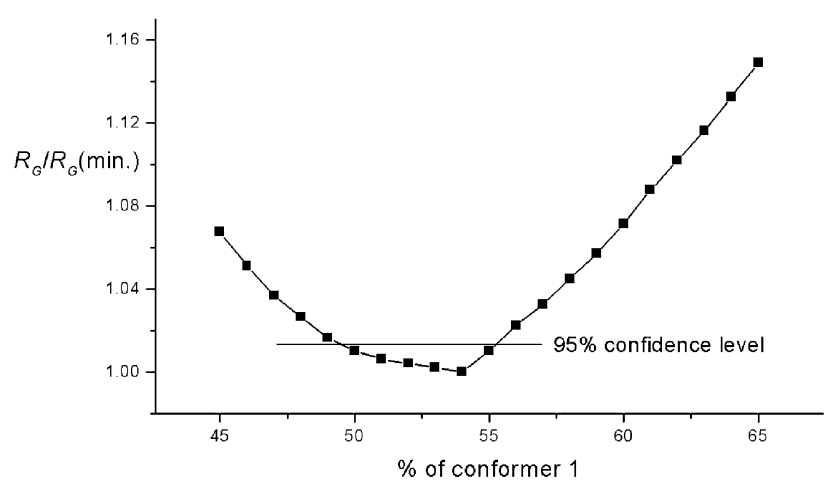

Fig. 4 Variations of $R_{\mathrm{G}}$ with percentage of conformer 1 of $\left(\mathrm{PF}_{2}\right) \mathrm{NH}\left(\mathrm{SiH}_{3}\right), \mathbf{8}$.

For a composition with $54 \%$ of conformer 1 and $46 \%$ of conformer 2 present, the lowest $R_{\mathrm{G}}$ value of 0.049 was obtained. Fig. S8 (ESI $\dagger$ ) shows the radial-distribution curve and the theoretical - experimental difference curve for the joint refinement assuming the abundance of conformer 1 to be $54 \%$. A least-squares correlation matrix is given in Table $\mathrm{S} 38$ (ESI $\dagger$ ).

The original GED refinement ${ }^{21}$ gave an $R_{\mathrm{G}}$ value of 0.098 and was interpreted in terms of two conformers, similar to those in this discussion.

\section{Discussion}

It was clear from studying the original gas-phase structures of the eight aminodifluorophosphines that, while they mostly achieved the same conformations that we have found in this work, numerous assumptions had been made. The use of structures calculated $a b$ initio and, consequently, the SARACEN method of restraining parameters, rather than fixing them, has allowed more complete structure determinations. Fig. 5 shows the improvement in the $R_{\mathrm{G}}$ values for seven of the eight compounds that were revisited and the average value has dropped from approximately 8.8 to $5.1 \%$. The case of $\left(\mathrm{PF}_{2}\right) \mathrm{NH}\left(\mathrm{CH}_{3}\right), 3$, has been omitted because the $R_{\mathrm{G}}$ value for the original refinement was not published. Another benefit of the inclusion of the new methods was a general lowering of the uncertainties associated with the refined parameter values. As a result, the structures are more precise than those previously published.



Fig. 5 Comparison of original and new $R$ factors for all compounds except $\mathbf{3}$, for which no original $R$ factor was recorded.

From consulting Table 1, trends can be observed in some of the bond lengths common to all the $r_{h 1}$ structures. In some instances, these trends were obscured by inaccuracies or uncertainties in the original structures. $\mathrm{N}\left(\mathrm{PF}_{2}\right)_{3}, 2$, with only the three difluorophosphine groups attached to the central nitrogen atom, is a good compound to use as a reference. The $\mathrm{N}-\mathrm{P}$ bonds in $\mathbf{2}$ are, at $173.5 \mathrm{pm}$, longer than in any of the other molecules except $\left(\mathrm{GeH}_{3}\right) \mathrm{N}\left(\mathrm{PF}_{2}\right)_{2}, 7 . \mathrm{N}\left(\mathrm{PF}_{2}\right)_{3}$ also displays some of the shortest $\mathrm{P}$ $\mathrm{F}$ bonds seen in the series of compounds. Conversely, the four compounds that contain only one difluorophosphine group have amongst the longest $\mathrm{P}-\mathrm{F}$ bond lengths and have values for the $\mathrm{N}-\mathrm{P}$ bond distance that are up to $4 \mathrm{pm}$ shorter than those found in 2. These findings are consistent with the nitrogen lone pair of electrons delocalising onto phosphorus. The $\mathrm{PF}_{2}$ groups will compete for the lone pair of electrons and so we see longer $\mathrm{P}-\mathrm{N}$ bonds for molecules with more $\mathrm{PF}_{2}$ groups. It is also noticeable that long $\mathrm{P}-\mathrm{N}$ bonds in a molecule correlate with shorter $\mathrm{P}-\mathrm{F}$ bonds.

All of the structures determined are either planar at $\mathrm{N}$ or deviate from planarity by only a few degrees. It is therefore valid to say that, in all cases, the lone pair of electrons on the nitrogen will lie at approximately $90^{\circ}$ to the $\mathrm{P}-\mathrm{N}$ bonds. It is also reasonable to say that the phosphorus lone pair will lie on the inverse of the centroid of the $\mathrm{N} \cdots \mathrm{F} \ldots \mathrm{F}$ triangle, as described in the method of Hinchley et al. ${ }^{22}$ Thus, a value can be calculated that corresponds to the dihedral angle formed between the nitrogen lone pair (Nlp) and that on the phosphorus (Plp). These values for $\phi \mathrm{Nlp}-\mathrm{N}-\mathrm{P}-\mathrm{Plp}$ are given in Table 2 and the values around $90^{\circ}$ indicate orthogonality between the lone pairs. As the lone pairs of electrons are not experimentally observable, and approximations have been made, no uncertainty has been quoted for any of the Nlp-N-P-Plp dihedral angles. 
Table 2 Experimentally derived torsional angles ${ }^{a}$ describing the position of the $\mathrm{PF}_{2}$ groups in terms of the phosphorus lone pair of electrons in relation to the nitrogen lone pair (see text for full definition)

\begin{tabular}{lll}
\hline Compound & Conformer & Torsional angle \\
\hline$\left(\mathrm{PF}_{2}\right)_{2} \mathrm{NH}$ & 1 & 74.3 \\
& 2 & $89.1[\mathrm{P}(2)]$ and $89.3[\mathrm{P}(5)]$ \\
$\mathrm{N}\left(\mathrm{PF}_{2}\right)_{3}$ & & $81.3($ all $)$ \\
$\left(\mathrm{PF}_{2}\right) \mathrm{NH}\left(\mathrm{CH}_{3}\right)$ & & 71.4 \\
$\left(\mathrm{PF}_{2}\right) \mathrm{N}\left(\mathrm{CH}_{3}\right)_{2}$ & & 86.5 \\
$\left(\mathrm{PF}_{2}\right)_{2} \mathrm{~N}\left(\mathrm{SiH}_{3}\right)$ & & 80.4 (both) \\
$\left(\mathrm{PF}_{2}\right) \mathrm{N}(\mathrm{SiH})_{2}$ & & 84.1 \\
$\left(\mathrm{PF}_{2}\right)_{2} \mathrm{~N}\left(\mathrm{GeH}_{3}\right)$ & & 80.1 (both) \\
$\left(\mathrm{PF}_{2}\right) \mathrm{NH}\left(\mathrm{SiH}_{3}\right)$ & 1 & 61.6 \\
& 2 & 86.1 \\
& & \\
${ }^{a}$ Angles in degrees. & & \\
\hline
\end{tabular}

\section{Acknowledgements}

We would like to thank everyone who has worked to collect data on these compounds in the past, without whom this reanalysis would be impossible. D. A. W. thanks the EPSRC and University of Edinburgh for jointly funding a studentship.

\section{References}

1 M. J. Frisch, G. W. Trucks, H. B. Schlegel, G. E. Scuseria, M. A. Robb, J. R. Cheeseman, V. G. Zakrzewski, J. A. Montgomery, Jr., R. E. Stratmann, J. C. Burant, S. Dapprich, J. M. Millam, A. D. Daniels, K. N. Kudin, M. C. Strain, O. Farkas, J. Tomasi, V. Barone, M. Cossi, R. Cammi, B. Mennucci, C. Pomelli, C. Adamo, S. Clifford, J. Ochterski, G. A. Petersson, P. Y. Ayala, Q. Cui, K. Morokuma, D. K. Malick, A. D. Rabuck, K. Raghavachari, J. B. Foresman, J. Cioslowski, J. V. Ortiz, A. G. Baboul, B. B. Stefanov, G. Liu, A. Liashenko, P. Piskorz, I. Komaromi, R. Gomperts, R. L. Martin, D. J. Fox, T. Keith, M. A. Al-Laham, C. Y. Peng, A. Nanayakkara, C. Gonzalez, M. Challacombe, P. M. W. Gill, B. G. Johnson, W. Chen, M. W. Wong, J. L. Andres, M. Head-Gordon, E. S. Replogle and J. A. Pople, Gaussian 98 (Revision A.7), Gaussian, Inc., Pittsburgh, PA, 1998.

2 Parallel Quantum Solutions, Fayetteville, Arkansas, USA.
3 J. S. Binkley, J. A. Pople and W. J. Hehre, J. Am. Chem. Soc., 1980, 102, 939; M. S. Gordon, J. S. Binkley, J. A. Pople, W. J. Pietro and W. J. Hehre, J. Am. Chem. Soc., 1982, 104, 2797; W. J. Pietro, M. M. Francl, W. J. Hehre, D. J. DeFrees, J. A. Pople and J. S. Binkley, J. Am. Chem. Soc., 1982, 104, 5039.

4 W. J. Hehre, R. Ditchfield and J. A. Pople, J. Chem. Phys., 1972, 56, 2257; P. C. Hariharan and J. A. Pople, Theor. Chim. Acta, 1973, 28, 213; M. S. Gordon, Chem. Phys. Lett., 1980, 76, 163.

5 A. D. McLean and G. S. Chandler, J. Chem. Phys., 1980, 72, 5639; R. Krishnan, J. S. Binkley, R. Seeger and J. A. Pople, J. Chem. Phys., $1980,72,650$.

6 V. A. Sipachev, J. Mol. Struct. (THEOCHEM), 1985, 121, 143.

7 UnGraph, Version 4.0, Biosoft ${ }^{\circledR}$ Professional Software, Inc.

8 A. J. Blake, P. T. Brain, H. McNab, J. Miller, C. A. Morrison, S. Parsons, D. W. H. Rankin, H. E. Robertson and B. A. Smart, J. Phys. Chem., 1996, 100, 12280; P. T. Brain, C. A. Morrison, S. Parsons and D. W. H. Rankin, J. Chem. Soc., Dalton Trans., 1996, 4589; N. W. Mitzel and D. W. H. Rankin, Dalton Trans., 2003, 3650.

9 E. Hedberg, L. Hedberg and K. Hedberg, J. Am. Chem. Soc., 1974, 96, 4417.

10 W. C. Hamilton, Acta Crystallogr., 1965, 18, 502.

11 C. M. Huntley, G. S. Laurenson and D. W. H. Rankin, J. Chem. Soc., Dalton Trans., 1980, 954.

12 D. E. J. Arnold and D. W. H. Rankin, J. Chem. Soc., Dalton Trans., 1975,889

13 D. E. J. Arnold, D. W. H. Rankin, M. R. Todd and R. Seip, J. Chem. Soc., Dalton Trans., 1979, 1290.

14 K. Hedberg, J. Am. Chem. Soc., 1955, 77, 6491; B. Beagley and A. R. Conrad, J. Chem. Soc., Faraday Trans., 1970, 2740.

15 G. S. Laurenson and D. W. H. Rankin, J. Mol. Struct., 1979, 54, 111.

16 P. Forti, D. Damiani and P. G. Favero, J. Am. Chem. Soc., 1973, 95, 756.

17 G. C. Holywell, D. W. H. Rankin, B. Beagley and J. M. Freeman, J. Chem. Soc. A, 1971, 785.

18 E. D. Morris, Jr. and C. E. Nordman, Inorg. Chem., 1969, 8, 1673.

19 G. S. Laurenson and D. W. H. Rankin, J. Chem. Soc., Dalton Trans., $1981,425$.

20 G. S. Laurenson and D. W. H. Rankin, J. Chem. Soc., Dalton Trans., 1981, 1047.

21 D. E. J. Arnold, E. A. V. Ebsworth, H. F. Jessop and D. W. H. Rankin, J. Chem. Soc., Dalton Trans., 1972, 1681

22 S. L. Hinchley, H. E. Robertson, D. W. H. Rankin and W.-W. du Mont, J. Chem. Soc., Dalton Trans., 2002, 3787. 